\section{Obituary Alexander H Glassman}

Neuropsychopharmacology (201 I) 36, 2791; doi: 10.1038/npp.201 I.231

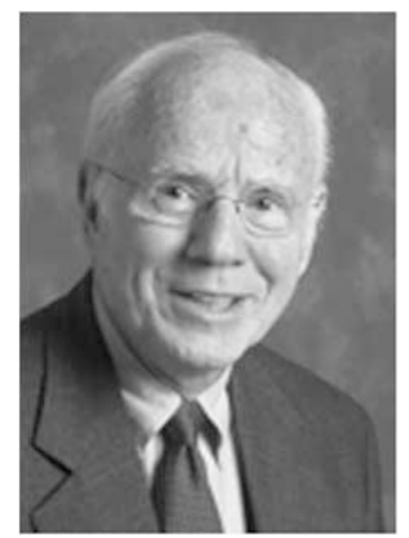

Alexander H. Glassman died on 19 July 2011. Dr Glassman was an internationally recognized clinical researcher whose innovative and scientifically rigorous contributions to our knowledge of serious mental illness changed the way medicine is practiced.

Dr Glassman was born in Chicago and received his MD degree from the University of Illinois. He joined the faculty of Albert Einstein College of Medicine in New York, and, after service in the United States Army, returned to New York and joined the faculty at Columbia in 1969, rising to the rank of Professor.

Dr Glassman was a prolific researcher with broad vision. His work was among the first to document that monitoring the blood concentration of antidepressant medication was an effective method of increasing treatment success. He was a pioneer and recognized expert on the impact of psychiatric medication on the heart, and the impact of depression on the development of heart disease. His work documented that mood disturbance following myocardial infarction was associated with a substantial increase in later mortality, and, in a seminal study, he showed that treatment of depression in this vulnerable population may well increase survival. In recent years, Dr Glassman established links between smoking and psychiatric illness, and formulated a neurobiological model that led to new treatments for nicotine addiction. His work was at the core of a sophisticated revision of our understanding of the relationship between the mind, brain, and the body.
He authored over 350 publications in every major journal in medicine. He received numerous awards and honors including the American Psychiatric Association's Foundation Fund Prize for Research, the New York State Research Award, the NARSAD Distinguished Investigators Award, and the Anna-Monika Foundation Prize. He lectured around the world and was an important contributor to scientific meetings for over four decades. As a member of the Columbia faculty for over 40 years, Dr Glassman trained generations of psychiatrists. It is a testament to his qualities as an extraordinarily wise and generous mentor that his students and younger colleagues have gone on to leadership roles in American psychiatry, with major accomplishments in a range of fields, including late-life depression, eating disorders, and academic administration.

Dr Glassman was accepted to membership in the ACNP in 1981 and was promoted to Fellow in 1990. During his 30 years of membership, he rarely missed an annual meeting, and always spent serious time on the tennis court as well as in lecture halls. He served as a member of the Neuropsychopharmacology Editorial Board and on the Publications, Liaison, and Membership committees. Additionally, in 2003, Dr Glassman was interviewed by ACNP member Dr Thomas Ban as a part of 10 volume ACNP project entitled An Oral History of Neuropsychopharmacology, Peer Interviews. His transcript will appear in Volume 7 of the series Special Areas to be released during the ACNPs 50th Anniversary meeting this December.

Dr Glassman was not only a devoted scientist but also an extraordinary clinician. His extensive knowledge of psychiatric illness, professional integrity, and exceptional devotion to his patients made him a most sought after consultant. He cared for his patients with warmth, wisdom, and humanity.

We deeply mourn the passing of our beloved friend, admired teacher, and distinguished colleague.

B Timothy Walsh ${ }^{1}$, Steven Roose ${ }^{1}$ and Jeffrey A Lieberman ${ }^{1}$ ${ }^{1}$ Department of Psychiatry, New York State Psychiatric Institute, Columbia University, New York, NY, USA E-mail: btw1@columbia.edu (BTW) or spr2@columbia.edu (SR) or jlieberman@columbia.edu (JAL) 